\title{
Correction to: Enhanced local recruitment of glass eel Anguilla japonica in Oyodo River, Miyazaki and offshore environmental conditions in 2002
}

\author{
Kazuhiro Aoki ${ }^{1} \cdot$ Toshihiro Yamamoto $^{2} \cdot$ Nobuto Fukuda $^{2} \cdot$ Kazuki Yokouchi $^{2} \cdot$ Hiroaki Kurogi $^{2} \cdot$ Takashi Setou $^{1}$. \\ Hiroshi Kuroda ${ }^{1,3} \cdot$ Takahiko Kameda $^{1} \cdot$ Kazuhiro Takafuji $^{4} \cdot$ Tsutomu Tokeshi $^{5}$
}

Published online: 11 August 2018

(c) Japanese Society of Fisheries Science 2018

\section{Correction to: Fisheries Science \\ https://doi.org/10.1007/s12562-018-1207-4}

In the original publication, Fig. 2 was published with incorrect values, as the definition of the fisheries season in this study (e.g., CPUE in the Oyodo River and environmental factors) differed from the definition for data of the total catch in Japan provided by the Japan Fisheries Agency (http:// www.jfa.maff.go.jp/j/saibai/unagi.html). In this study, the total catch in Japan in year $x$ after 2002 was calculated using catch data from November in year $(x-1)$ to October in year $x$. Annual total catch values up to the year 2001 were obtained from the statistical yearbook of the Ministry of Aquaculture, Forestry and Fisheries, Japan. In addition, the caption of Fig. 2 was incorrect. The amended caption and graphic for Fig. 2 are provided in this correction.
Kazuhiro Aoki

kazuaoki@affrc.go.jp

1 Japan Fisheries Research and Education Agency, National Research Institute of Fisheries Science, 2-12-4 Fukuura, Kanazawa, Yokohama, Kanagawa 236-8648, Japan

2 Arasaki Marine Biological Station, Japan Fisheries Research and Education Agency, National Research Institute of Fisheries Science, 6-31-1 Nagai, Yokosuka, Kanagawa 238-0316, Japan

3 Japan Fisheries Research and Education Agency, Hokkaido National Fisheries Research Institute, 116 Katsurakoi, Kushiro, Hokkaido 085-0802, Japan

4 Miyazaki Prefectural Inland Waters Fisheries Promotion Center, 3992-2 Sadowarachoshimonakaazakakoi, Miyazaki 880-0212, Japan

5 Fisheries Research Institute, Miyazaki Prefectural Government, 6-16-3 Aoshima, Miyazaki, Miyazaki 889-2162, Japan 


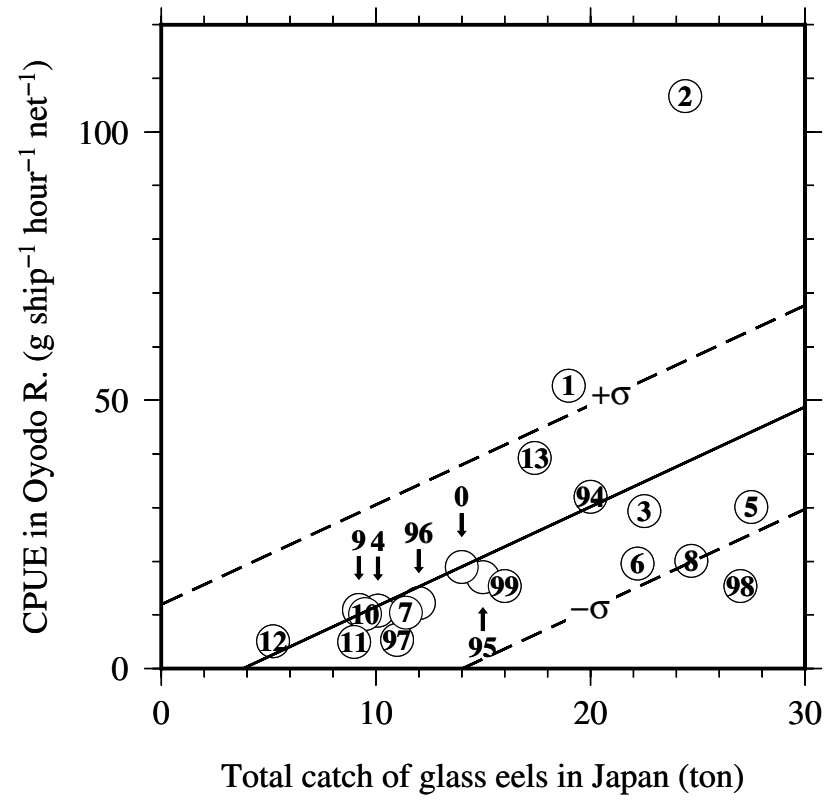

Fig. 2 Relationship between CPUE in the Oyodo River and the total catch per year of glass eels in Japan. The data point for a particular year is marked by a number in a circle, where the number indicates the year (e.g., the circle with a " 2 " inside corresponds to the data point for 2002). The bold and dashed lines in the plot indicate the regression line and the root-mean-square error, respectively.
Moreover, in the section "Yearly variation of CPUE," the second and third sentences were incorrect. They should have read as follows:

"Unusually high glass eel recruitment was observed in 2002, which is reflected in Fig. 2 by a large deviation of the data point for 2002 from the regression line between the CPUE in the Oyodo River and the total catch of glass eels in Japan."

However, the authors consider that these errors do not influence the main results and conclusions of this study of the main factors that enhanced the local recruitment of the glass eel Anguilla japonica in the Oyodo River in 2002. 